\title{
Recycler Reaction for the Government Behavior in Closed-Loop Supply Chain Distribution Network: Based on the System Dynamics
}

\author{
Xi gang Yuan $^{1}$ and Xiao qing Zhang ${ }^{2}$ \\ ${ }^{1}$ School of Statistics, Southwest University of Financial and Economics, Chengdu, Sichuan 611130, China \\ ${ }^{2}$ School of Management, Guangxi University of Science and Technology, Liu Zhou, Guangxi 545006, China \\ Correspondence should be addressed to Xi gang Yuan; 1038223569@qq.com
}

Received 17 December 2014; Accepted 25 January 2015

Academic Editor: Essam Radwan

Copyright (c) 2015 X. G. Yuan and X. Q. Zhang. This is an open access article distributed under the Creative Commons Attribution License, which permits unrestricted use, distribution, and reproduction in any medium, provided the original work is properly cited.

\begin{abstract}
With system dynamics, we establish three-closed-loop supply chain distribution network system model which consists of supplier, manufacturer, two retailers, and products (parts) recycler. We proposed that recycler make reflect for the government policy by adjusting the recycling ratio and recycling delay. We use vensim software to simulate this model and investigate how the products (parts) recyclers behavior influences the loop supply chain distribution system. The result shows that (1) when recyclers respond positively to government policies, recycling will increase the proportion of recyclers. When recyclers respond negatively to government policy making, recycling will reduce the proportion of recyclers. (2) When the recovery percentage of recyclers improves, manufacturers, Retailer 1, and Retailer 2 quantity fluctuations will reduce and the bullwhip effect will diminish. (3) When the proportion of recycled parts recyclers is lowered, manufacturers, Retailer 1, and Retailer 2 inventory fluctuation will increase and the bullwhip effect will be enhanced. (4) When recyclers recycling product delays increased, volatility manufacturers order quantity will rise, but there is little change in the amount of fluctuation of orders of the two retailers. (5) When recycling parts recyclers delay increases, fluctuations in the supplier order quantity will rise, but there is little change in the amount of fluctuation of orders of the two retailers.
\end{abstract}

\section{Introduction}

Nowadays, closed-loop supply chain distribution network system has become a new research point since people pursue circular economy and social sustainable development. Closed-loop supply chain distribution system is a new supply chain form in circular economy. van Wassnhove et al. [1] and Guide Jr. et al. [2] have researched the closed-loop supply chain; they think that we can build a complete closed-loop supply chain distribution network system which includes supply, manufacturing, retail, and recycling and is based on the traditional supply chain and adds to products (parts) recycler.

With products (parts) recycler adding to the supply chain distribution network system, it makes the nature of the supply chain distribution network system gradually changed. Domestic and foreign scholars deeply discuss cooperation mechanism between various members in the supply chain distribution network system. Savaskan et al. [3] and Savaskan and van Wassenhove [4] research the cooperation mechanism problem between manufacturers and retailers under symmetric information with the recycler participating in the supply chain. Forrester [5], Sterman [6], and Baik [7] mainly discuss the cooperative factors and competitive factors in the supply chain distribution network system and come up with the corresponding cooperation strategy. Then, Liu et al. [8] consider competitive factors in different supply chain distribution network system and establish appropriate cooperation model and propose effective solving measure. 
Based on the abovementioned articles, many scholars research the bullwhip effect problem in the closed-loop supply chain distribution network system. Based on the twostage supply chain [8], Wan and Li [9] increase recycling logistics, and they research the bullwhip effect in the closedloop supply chain distribution network system. Because the recycler participates in the supply chain, it causes the bullwhip effect in the supply chain distribution network system. Forrester [10] analyzes a traditional supply chain and observes how a small change in a customer's demand pattern amplifies as it flows through distribution, production, and replenishment processes. Burbidge [11, 12] presents the so-called PBC (period batch control), which develops the five golden rules to avoid bankruptcy. Subsequently, Towill [13] integrates Forrester and Burbidge's concepts to develop a series of improved communication and materials flow practices in the supply chain. Lee et al. [14] research how the structure of different supply chain types influences the bullwhip effect. Holmström [15] analyzes the bullwhip effect in a supply chain of the grocery industry; Towill and McCullen [16] study the bullwhip effect in a clothes supply chain, while Daganzo [17] unveils the core causes of the bullwhip effect and describes control methods for eliminating all instabilities without increasing supplier costs. However, Sterman [18] provides the best illustration of the bullwhip effect, investigating how human errors affect the dynamics of a system through its well-known business game, the so-called Beer Game, from the performance science perspective, but did not consider the circumstances under asymmetric information.

As can be seen from the abovementioned articles, the shortage of normal research is as follows. Firstly, most articles are limited to accessing the single closed-loop supply chain distribution system; few scholars research the bullwhip effect in the supply chain distribution network system which consists of multiple manufacturers and multiple retailers. And then, few scholars research recycler's reaction to the government policy in the supply chain distribution network system.

Based on the above research, we establish a three-closedloop supply chain distribution system dynamics model which consists of supplier, manufacturer, two retailers, and products (parts) recycler. We research the influence of each member in supply chain distribution system under different recycling ratios and different recycling delay, thus revealing the impact of product (parts) recycler's behavior on the entire closedloop supply chain distribution system.

The rest of this paper is organized as follows. In Section 2 we establish a closed-loop supply chain distribution system dynamics model. In Section 3 we illustrate our model using numerical examples. Concluding remarks are given in Section 4.

\section{Closed-Loop Supply Chain Distribution System Dynamics Model}

In the paper, we establish a closed-loop supply chain distribution system dynamics model by vensim PLE. The model consists of a supplier, a manufacturer, two retailers, and a products (parts) recycler. The supply chain starts from supplier supplying new parts and recycling old parts, manufacturer sailing some products to two retailers, products (parts), and recyclers recycling old products, thus constituting a complete closed-loop supply chain distribution system.

2.1. Model Assumption. The assumption in supply chain distribution system model is as follows.

(1) Suppliers' products (parts) capacity, manufacturers' production capacity, retailers' sale capacity, and transport capacity all have no restriction; products (parts) recyclers recycling products and components capacity have no restriction.

(2) The price of recycling products and parts is equal to new products price; old parts and products are recycled by the manufacturer; manufacturer or supplier is not recycling old parts or old products.

(3) Customer does not discriminate the remanufacturing products and remanufactured parts; customer has the same demand for new products and remanufactured products (parts).

(4) In the paper, using two retailers' market rates, we measure the customer's demand; if two retailers' market rate is high, it indicates that customer's demand is high.

2.2. System Dynamics Model. In the paper, closed-loop supply chain distribution system consists of a supplier, a manufacturer, two retailers, and a products (parts) recycler; in the middle, any link does not appear out of stock. We establish the supply chain distribution system as shown in Figure 1.

In Table 1 and Figure 1, we can find that suppliers' inventory is decided by suppliers' products delay time, parts productivity, recycled parts remanufacturing rate, and suppliers' delivery rate. Manufacturers' inventory is decided by suppliers' delivery rate, recycled products remanufacturing rate, manufacturers' products delay time, and manufacturers' shipment ratio to two retailers. Retailer 1 inventory is decided by market sale's rate and transportation delay time 1. Retailer 2 inventory is decided by market sale's rate and transportation delay time 2. Order of Retailers 1 and 2, the needs for manufacturer's products, and the needs for suppliers' products (parts) are decided by sales forecast, inventory adjustment, and inventory adjustment time. The recycler recycles the waste products (parts) from market. Some recovered products (parts) are directly discarded, some recovered products (parts) for are kept further processing, recycling old products directly flow to the manufacturer, recycling old parts directly flow to the supplier, then parts go through distribution and transport to reach the hands of customers, and this cycle forms a complete closed-loop. We can establish the flow chat of the supply chain distribution network in Figure 2 and the system dynamics model in Figure 3. 


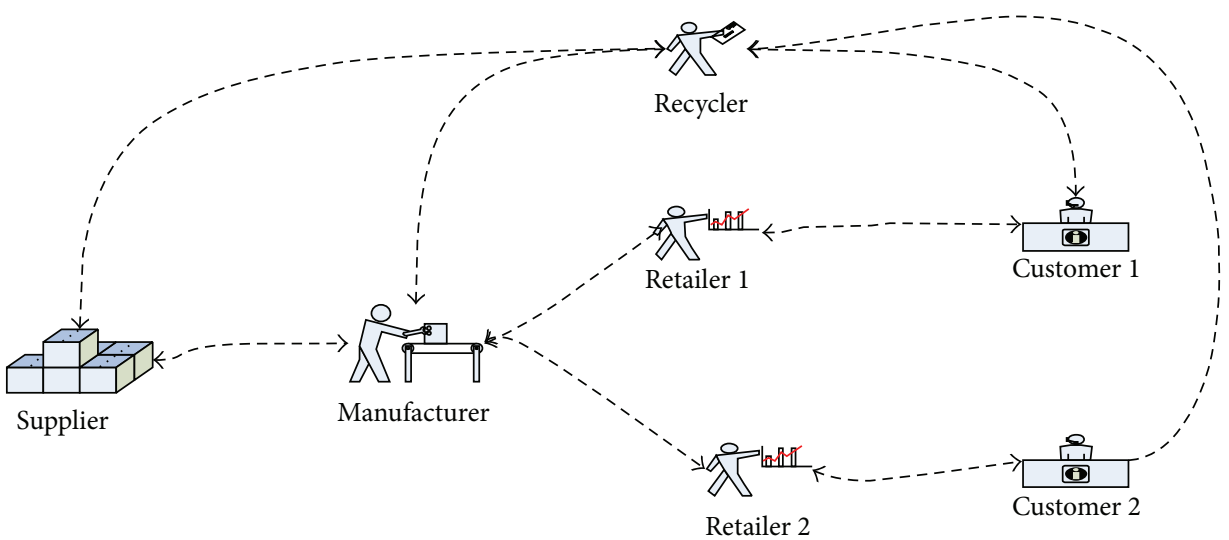

FIGURE 1: Supply chain distribution system conceptual model.

TABLE 1: Model constants set.

\begin{tabular}{lccc}
\hline Parameters & Value & Parameters & Value \\
\hline Inventory adjustment time & 28 & Manufacturer product delay & 14 \\
Supplier product delay & 14 & Retailer 2 transportation delay & 14 \\
Retailer 1 transportation delay & 14 & Moving average period number & 14 \\
Expect inventory sustainable time & 21 & Manufacture delivery delay & 14 \\
Recycling product adjustment time & 14 & $\langle$ Time2 & 12 \\
$\langle$ Timel $\rangle$ & 12 & Supplier delivery delay & 14 \\
\hline
\end{tabular}

\section{Main Parameters and System Dynamics Equation}

3.1. Supplier's Main Equation. Supplier inventory is a stock variable, inflow variables are parts productivity and recycled parts remanufactured rate, and the out of flow variable is delivery rate from supplier to manufacturer. Delivery rate from supplier to manufacturer is based on manufacturer's production orders. Parts productivity is equal to supplier production order. Supplier's expected inventory and supplier's sale forecast are based on the sustainable time of expected inventory. Supplier's parts production consists of supplier's new product and recycled parts remanufacturing product. Supplier's new production order is equal to supplier's production demand rate minus recycled parts remanufactured rate. Supplier's sale forecast is the smoothing function for supplier delivery rate. The function is as follows:

Supplier inventory

= DELAY3I (Parts productivity, Delivery delay of the supplier's, Supplier production delays time)

+ Recycled parts remanufactured rate

- Delivery rate from supplier to manufacturer;
Supplier production demand rate

$$
\begin{aligned}
& =\operatorname{MAX}(\text { 0, Supplier's sale forecast } \\
& +\frac{\text { Supplier's expect inventory }}{\text { Inventory adjustment time }} \\
& \left.-\frac{\text { Supplier inventory }}{\text { Inventory adjustment time }}\right) ;
\end{aligned}
$$

Supplier's sale forecast

$=$ SMOOTH $($ Delivery rate from supplier to manufacturer, Average moving period time);

Delivery rate from supplier to manufacturer

= DELAY3 (Manufacturer production order, Delivery delay of the supplier's);

Supplier production orders

$=$ Supplier production demand rate

- Recycled parts remanufactured rate; 


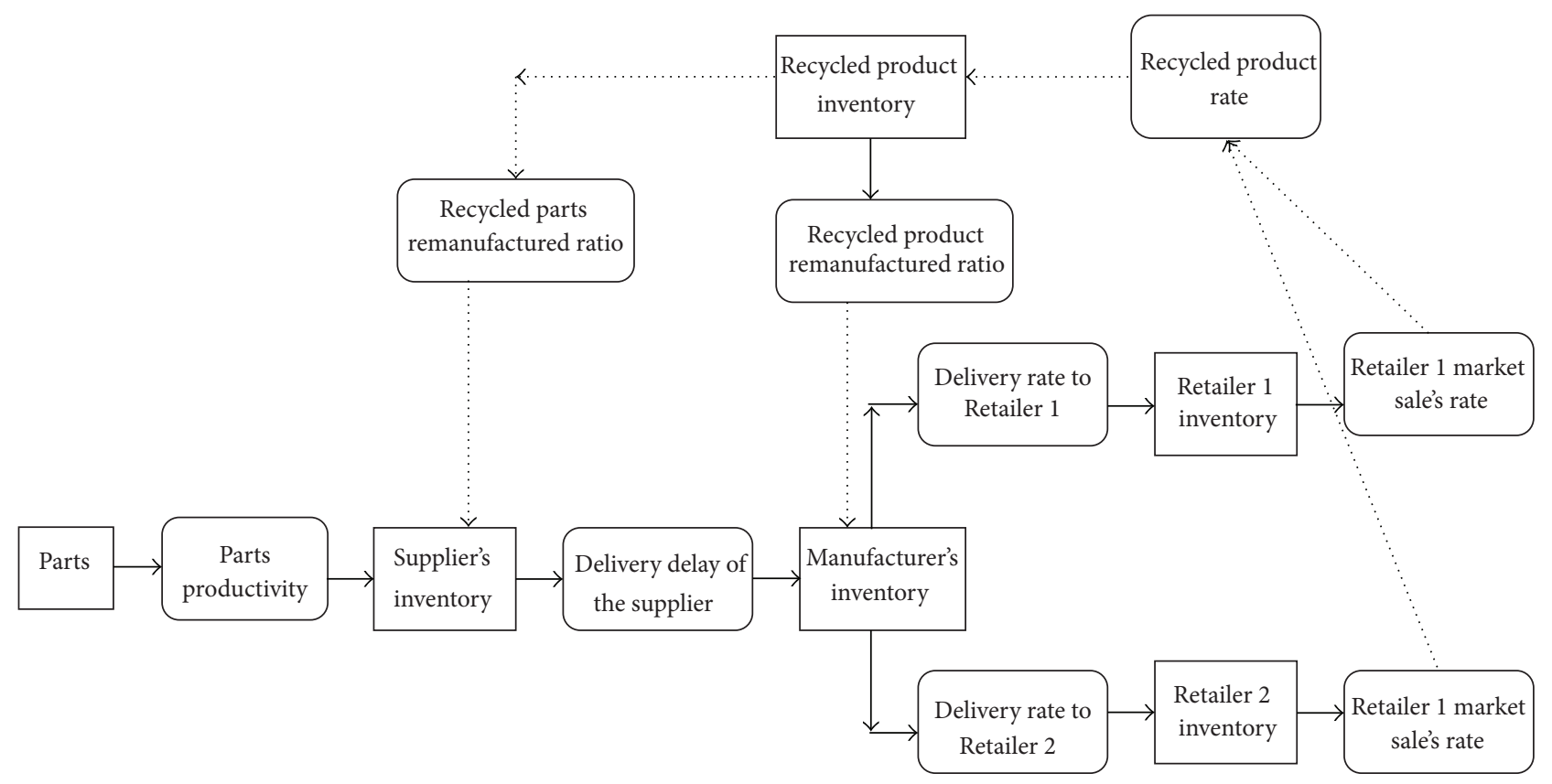

FIgURE 2: Flow chat of the supply chain distribution system.

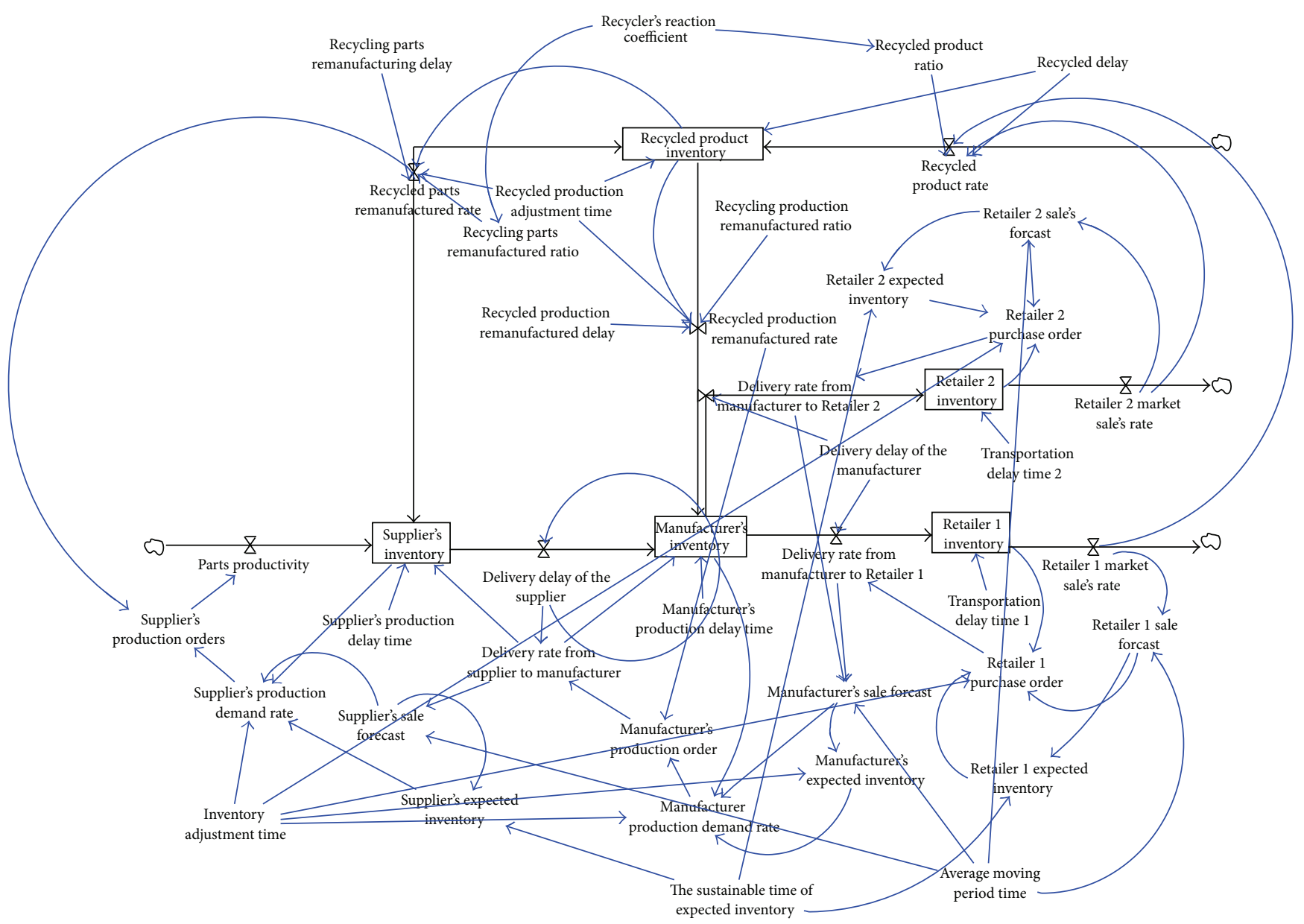

FIGURE 3: Closed-loop supply chain distribution network system dynamics flow diagram. 
Supplier's expect inventory

$=$ Supplier's sale forecast

* the sustainable time of expect inventory;

Parts productivity $=$ Supplier production orders.

3.2. Manufacturer's Main Equation. Manufacturer inventory is a stock variable, inflow variables are delivery rate from supplier to manufacturer and recycled production remanufactured rate, and the out of flow variables are delivery rate from manufacturer to Retailer 1 and delivery rate from manufacturer to Retailer 2. Delivery rate from manufacturer to Retailer 1 is based on Retailer 1 sale orders. Delivery rate from manufacturer to Retailer 2 is based on retailer 2 sale orders. Manufacturer's expected inventory and manufacturer's sale forecast are based on the sustainable time of expect inventory. Manufacturer production order is equal to manufacturer production demand rate minus recycled production remanufactured rate. Manufacturer sale forecast is the smoothing function for manufacturer delivery rate. The function is as follows:

\section{Manufacturer inventory}

= DELAY3I (Delivery rate from

supplier to manufacturer,

Manufacturer production delays time,

Delivery delay of the supplier's)

+ Recycled production remanufactured rate

- Delivery rate from manufacturerto retailer 1

- Delivery rate from manufacturer to retailer 2;

Manufacturer production order

$=\operatorname{MAX}(0$, Manufacturer production demand rate

-Recycled production remanufactured rate);

Manufacturer production demand rate

$=\operatorname{MAX}(0$, Manufacturer's sale forecast

$$
\begin{aligned}
& +\frac{\text { Manufacturer expect inventory }}{\text { Inventory adjustment time }} \\
& \left.-\frac{\text { Manufacturer inventory }}{\text { Inventory adjustment time }}\right) ;
\end{aligned}
$$

Manufacturer expect inventory

$=$ Inventory adjustment time

* Manufacturer's sale forecast;
Manufacturer's sale forecast

= SMOOTH3I (Delivery rate from manufacturer to retailer 1 , Delivery rate from manufacturer to retailer 2 , Average moving period time).

3.3. Retailer 1 and Retailer 2 Main Equation. Retailer 1 inventory and Retailer 2 inventory are all stock variable, inflow variables are delivery rate from manufacturer to Retailer 1 and delivery rate from manufacturer to Retailer 2, and the out of flow variables are Retailer 1 market sale's rate and Retailer 2 sale's rate. Retailer 1 expected inventory and Retailer 1 sale forecast are based on the sustainable time of expect inventory. Retailer 2 expected inventory and Retailer 2 sale forecast are based on the sustainable time of expect inventory. Retailer 1 purchase order is related to Retailer 1 sale forecast, Retailer 1 expected inventory, and inventory adjustment time. Retailer 2 purchase order is related to Retailer 2 sale forecast, Retailer 2 expected inventory, and inventory adjustment time. Retailer 1 sale forecast is the smoothing function for Retailer 1 market sale's rate. Retailer 2 sale forecast is the smoothing function for Retailer 2 market sale's rate. The function is as follows:

Retailer 1 inventory

= DELAY3 (Delivery rate from manufacturer to retailer 1 , Transportation delay 1 )

- Retailer 1 market sale's rate;

Delivery rate from manufacturer to retailer 1

= DELAY3 (Retailer 1 purchase order, Delivery delay of the manufacturer's);

Retailer 1 expect inventory

$=$ Retailer's 1 sale forecast

* the sustainable time of expect inventory;

Retailer 1 purchase order

$$
\begin{aligned}
&=\operatorname{MAX}(0, \text { Retailer's } 1 \text { sale forecast } \\
&+\frac{\text { Retailer } 1 \text { expect inventory }}{\text { Inventory adjustment time }} \\
&\left.-\frac{\text { Retailer } 1 \text { inventory }}{\text { Inventory adjustment time }}\right) ;
\end{aligned}
$$


Retailer's 1 sale forecast

= SMOOTH (Retailer 1 market sale's rate, Average moving period time);

Retailer 2 inventory

= DELAY3 (Delivery rate from manufacturer

to retailer 2, Transportation delay 2)

- Retailer 2 market sale’s rate;

Retailer 2 purchase order

$=\operatorname{MAX}(0$, Retailer 2 sale's forecast

$+\frac{\text { Retailer } 2 \text { expect inventory }}{\text { Inventory adjustment time }}$

$\left.-\frac{\text { Retailer } 2 \text { inventory }}{\text { Inventory adjustment time }}\right)$;

Retailer's 2 sale forecast

= SMOOTH (Retailer 2 market sale's rate, Average moving period time);

Delivery rate from manufacturer to retailer 2

= DELAY3 (Retailer 2 purchase order,

Delivery delay of the manufacturer's);

Retailer 2 expect inventory

$=$ Retailer's 2 sale forecast

* the sustainable time of expect inventory.

3.4. Recycler's Main Equation. Recycled product inventory is a stock variable, inflow variables are recycled product rate and recycled production adjustment time, and the out of flow variables are recycled production remanufactured rate and recycled parts remanufactured rate. Recycled production remanufactured rate is based on the recycled production remanufactured delay. Recycled production rate is based on recycled product ratio, Retailer 1 market sale's rate, recycled product ratio, and Retailer 2 market sale's rate. Recycled parts remanufactured rate is mainly based on the recycled production remanufactured delay and recycling parts remanufactured ratio. The function is as follows:

Recycled product inventory

= DELAY3 (Recycled delay, Recycled product rate * Recycled production adjustment time)
- Recycled production remanufactured rate

- Recycled parts remanufactured rate;

Recycled production remanufactured rate

= DELAY3 (Recycled product inventory

$* \frac{\text { Recycling production remanufactured ratio }}{\text { Recycled production adjustment time }}$,

Recycled production remanufactured delay);

Recycled product rate

$=$ DELAY1 (Recycled product ratio

* Retailer 1 market sale's rate,

Recycled product ratio

* Retailer 2 market sale's rate,

Recycled delay);

Recycled parts remanufactured rate

= DELAY3 (Recycled product inventory

* $\frac{\text { Recycling parts remanufactured ratio }}{\text { Recycled production adjustment time }}$

Recycling parts remanufacturing delay).

\section{System Dynamics Simulation Model Which Is Recycler's Reaction to the Government Policy in Closed-Loop Supply Chain Distribution Network}

In closed-loop supply chain distribution network, recycler's products recycled rate is based on the recycled ratio. We assume that recycler recycles the old product at a certain proportion. When the manufacturer produces products, recycler predicts the manufacturer's remanufacturing order, according to the manufacturer's remanufacturing rate, and determines their own recycling ratio. The higher the remanufacturing order, the higher the recycling ratio. In 2009, "the circular economy promotion law of China" can be promulgated. In 2011, the regulation of the waste electrical electronic products recycling and dealing can be promulgated. It is more important for us to protect the environment around us. Our government comes up with the "producer responsibility system"; it asks the producer not only to be responsible for the environment pollution in the process of production but they should also be responsible for the environment pollution in the whole life cycle. Based on above, we propose recycler's reaction coefficient to respond for the environment policy such as the law or policy of mentioned above. We assume that the recycler reaction coefficients are $-1,0,1$. When recycler makes positive response to the government environment policy, the recycler reaction coefficient is 1 ; when recycler 
makes no response to the government environment policy, the recycler reflection coefficient is 0 ; when recycler makes negative response to the government environment policy, the recycler reflection coefficient is -1 .

Recycler's products recycled rate $=$ DELAY1 (products recycled ratio $*$ Retailer 1 market sale's rate and recycling delay time) + DELAY1(products recycled ratio $*$ Retailer 2 market sale's rate and recycling delay time). As can be seen from the above equation, recyclers recycling behavior is mainly affected by the recycled ratio and recycled delay time.

Based on the above research, we assumed the following.

Assumption 1. When recycler makes positive response to the government policy, recycler will increase the recycling rate; when recycler makes negative response to the government policy, recycler will decrease the recycling rate.

Assumption 2. When recyclers increase the recycling rate, manufacturers, Retailer 1, and Retailer 2 will decrease inventory, and the bullwhip effect will be weak.

Assumption 3. When recyclers decrease the recycling rate, manufacturers, Retailer 1, and Retailer 2 will increase inventory, and the bullwhip effect will be enhanced.

4.1. Numerical Examples. Based on the above assumptions, we establish system dynamics model verifying the accuracy of the above assumptions. In the paper, the set for mathematical equations about recycling ratio are as follows:

Product recycling ratio

$=$ recyclers' reaction coefficient

* (baseline product recycling ratio

$+\alpha_{1} *$ product reproduction ordering ratio $)^{1 / 2}$,

Parts recycling ratio

$=$ recyclers' reaction coefficient

* (baseline parts recycling ratio

$$
\left.+\alpha_{2} * \text { parts reproduction ordering ratio }\right)^{1 / 2} \text {. }
$$

When we use the system dynamics simulation, the baseline product recycling ratio is 0.1 , the baseline parts recycling ratio is 0.2 , parts recycling delay time is 14 days, product recycling delay time is 21 days, and recycler reaction coefficients are $-1,0$, and 1 . When recycler makes positive response to the government policy, the recycler reaction coefficient is 1 ; when recycler makes no response to the government policy, the recycler reflection coefficient is 0 ; when recycler makes negative response to the government policy, the recycler reflection coefficient is -1 . We can get

$$
\begin{gathered}
\alpha_{1}=\left(\frac{\text { product recycling ratio }^{2}}{\text { recyclers' reaction coefficient }}\right. \\
\quad \text { - baseline product recycling ratio }) \\
\cdot(\text { product reproduction ordering rate })^{-1}, \\
\alpha_{2}=\left(\frac{\text { parts recycling ratio }^{2}}{\text { recyclers' reaction coefficient }}\right. \\
\quad-\text { baseline parts recycling ratio }) \\
\cdot(\text { parts reproduction ordering rate })^{-1} .
\end{gathered}
$$

Combination with the simulation result of specific model, $\alpha_{1}=0.000001$, and $\alpha_{2}=0.000002$ results in

Product recycling ratio

$$
\begin{aligned}
& =\text { recyclers' reaction coefficient } \\
& *(\text { baseline product recycling ratio }+0.000001 \\
& \quad * \text { product reproduction ordering rate })^{1 / 2},
\end{aligned}
$$

Part recycled ratio

$$
\begin{aligned}
& =\text { recyclers' reaction coefficient } \\
& * \text { (baseline parts recycling ratio }+0.000002 \\
& \quad * \text { parts reproduction ordering rate })^{1 / 2}
\end{aligned}
$$

4.2. Research on Recycler Reaction Coefficient in System Dynamics. Simulation setting is as follows: INITIAL TIME $=0$ days, FINALTIME $=4000$ days, TIME STEP $=1$ day, SAVEPER = TIME STEP; the simulation period is 4000 days, one day for a step.

\subsubsection{The Change of Recycling Ratio under Different Reaction Coefficient}

(1) Product Recycling Ratio under Different Recyclers Reflection Coefficient. As can be seen from Figure 4, run 1 is product recycling ratio when recycler reaction coefficient is 1 ; run 2 is product recycling ratio when recycler reaction coefficient is 0 ; run 3 is product recycling ratio when recycler reaction coefficient is -1 . This also shows that when recycler makes positive response to the government policy, recycler will increase recycling ratio and when recycler makes negative response to the government policy, recycler will reduce the recycling ratio. 


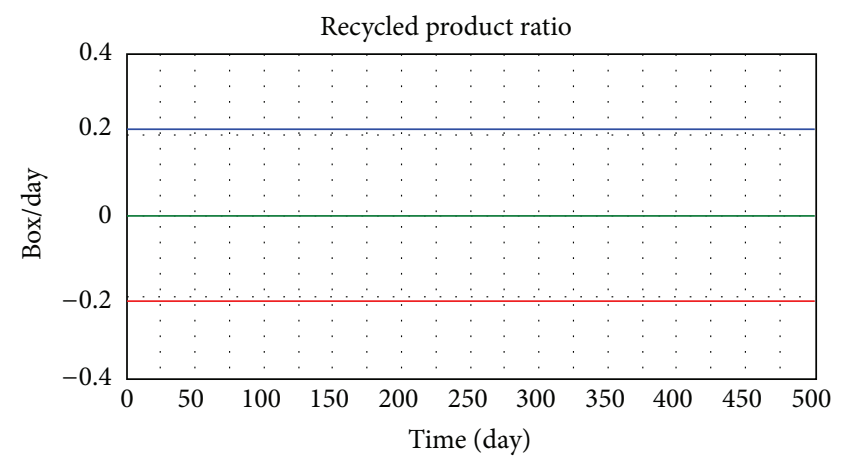

- Recycled product ratio: run 1

- Recycled product ratio: run 3

- Recycled product ratio: run 2

FIGURE 4: Product recycling ratio under different recycler reaction coefficients.

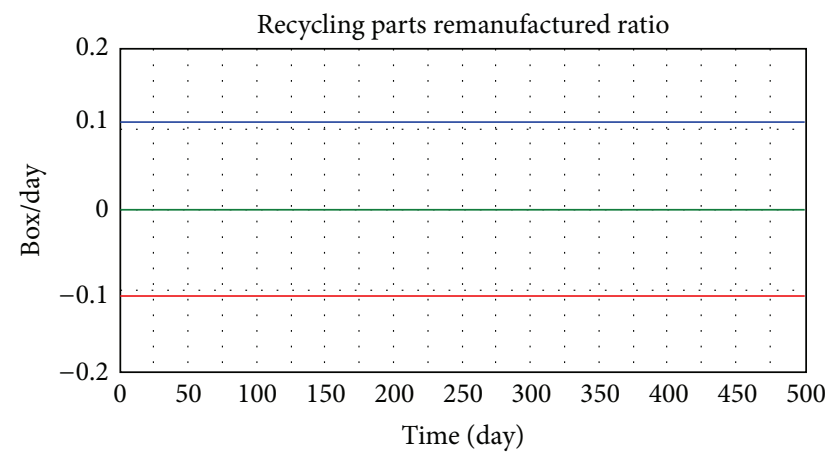

_ Recycling parts remanufactured ratio: run 1

- Recycling parts remanufactured ratio: run 3

— Recycling parts remanufactured ratio: run 2

FIGURE 5: Parts recycling ratio under different recycler reaction coefficients.

4.2.2. Parts Recycling Ratio under Different Recycler Reaction Coefficient. As can be seen from Figure 5, and Table 2 run 1 is parts recycling ratio when recycler reaction coefficient is 1 ; run 2 is parts recycling ratio when recycler reaction coefficient is 0 ; run 3 is parts recycling ratio when recycler reaction coefficient is -1 . This also shows that when recyclers make positive response to the government policy, recycler will increase recycling ratio and when recyclers make negative response to the government policy and the various members' order changes in the supply chain distribution network under different recyclers reflection coefficient and recycling delay.

(1) Various Members' Order Changes in the Supply Chain Distribution Network under Different Recyclers Reflection Coefficient. The main difference between the traditional supply chain model and the supply chain distribution network model established in this paper is that we add two retailers. As a result, the relationship is more complex in this supply chain. We consider when recycler reaction coefficient changes, how the order changes in manufacturer and two retailers.

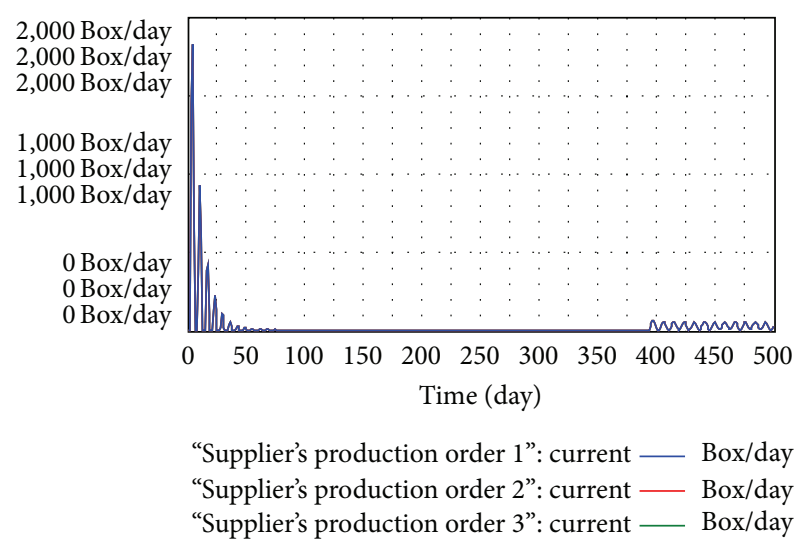

FIgURE 6: The members' order quantity changes when recycler reaction coefficient is 1 .

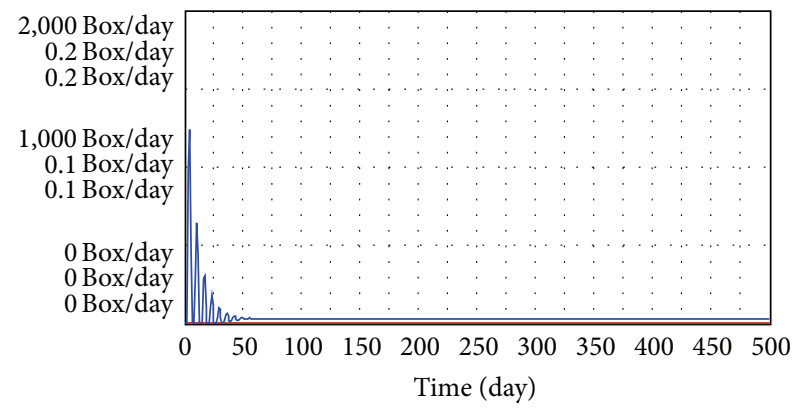

Manufacturer's production order: current —- Box/day
"Retailer's production order 1": current - Box/day
"Retailer's production order 2": current $\quad$ Box/day

Figure 7: The members' order quantity changes when recycler reaction coefficient is 2 .

As can be seen from the Figures 6, 7, and 8, when recycler reaction coefficient is 1 , the fluctuation of order quantity is very large in each of the members, range bound between 0 and 2000. When recycler reaction coefficient is 2 , the fluctuation of order quantity in each member is decreased; when recycler reaction coefficient is 3 , the fluctuation of order quantity in each member reduces between 0 and 1000 . With recycler reaction coefficient increasing, order quantity in each member gradually reduces.

We introduce the variation coefficient in the financial management and quantify the bullwhip effect in the closedloop supply chain distribution network:

$$
\text { Bullwhip effect }=\frac{\delta\left(x_{i}\right) / E\left(x_{i}\right)}{\delta\left(y_{i}\right) / E\left(y_{i}\right)},
$$

where $\delta\left(x_{i}\right)$ is said to be the standard of the order rate, $E\left(x_{i}\right)$ is said to be the expectation of the order rate, $\delta(y)$ is said to be the standard of the market sailor rate, and $E(x)$ is said to be the expectation of the market sailor rate.

(2) The Effect of Recycled Products Delay on the Order Quantity in Manufacturers and Two Retailers. As can be seen from the Figures 9, 10, and 11, and Table 3 with the increase of 
TABLE 2: Bullwhip effect of the order quantity of each member under different recycler's coefficient.

\begin{tabular}{lccc}
\hline & Recycler reaction coefficient is 1 & Recycler reaction coefficient is 2 & Recycler reaction coefficient is 3 \\
\hline Manufacturer order quantity & 105.32 & 100.08 & 98.24 \\
Retailer 1 order quantity & 85.24 & 79.201 & 68.204 \\
Retailer 2 order quantity & 83.054 & 77.204 & 65.38 \\
\hline
\end{tabular}

TABLE 3: The bullwhip effect when product recycling delay times are different (3) parts recycling delay’s influence on supplier and two retailers.

\begin{tabular}{lccc}
\hline & Recyclers reflection coefficient is 1 & Recyclers reflection coefficient is 2 & Recyclers reflection coefficient is 3 \\
\hline Manufacturer order quantity & 105.32 & 120.52 & 140.25 \\
Retailer 1 order quantity & 85.24 & 86.32 & 88.27 \\
Retailer 2 order quantity & 83.56 & 84.22 & 86.57
\end{tabular}

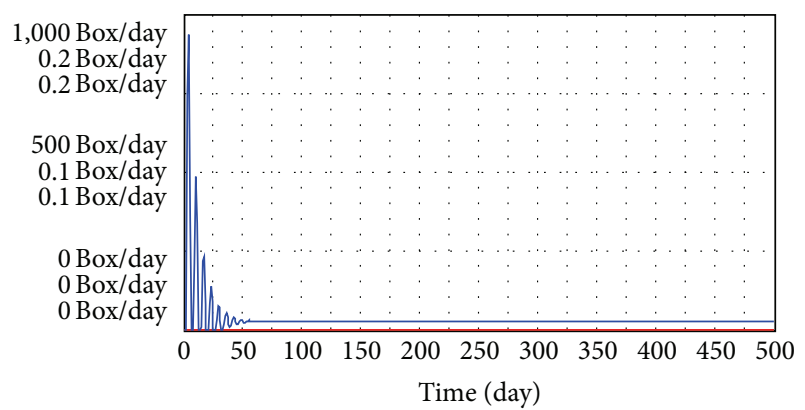

Manufacturer's production order: current — Box/day

"Retailer's production order 1": current Box/day

"Retailer's production order 2": current — Box/day

FIGURE 8: The members' order quantity changes when recycler reaction coefficient is 3 .

recycling product delay time, fluctuations of the order in the two retailers did not change much; at the same time, with the increasing of the recycled product delay time, fluctuation of the order in manufacturer gradually increases. This is mainly due to the recycling product delay time directly affecting changes in the manufacturer's order.

(3) Parts Recycling Delay's Influence on Supplier and Two Retailers. As can be seen from the Figures 12, 13, and 14, and Table 4 with the parts recycling delay time increasing, fluctuations of the order in two retailers did not change much; at the same time, with the parts recycling delay time increasing, fluctuation of the order in manufacturer gradually increases. This is mainly due to the parts recycling delay time directly affecting changes of the manufacturer's order.

\section{Conclusion}

In this paper, we research the different reflection of recyclers on the government policy. We can get the conclusion that (1) when recyclers respond positively to government policies, recycling will increase the proportion of recyclers. When recyclers respond negatively to government policy making, recycling will reduce the proportion of recyclers. (2) When the recovery percentage of recyclers improves, manufacturers, Retailer 1, and Retailer 2 order quantity fluctuations will

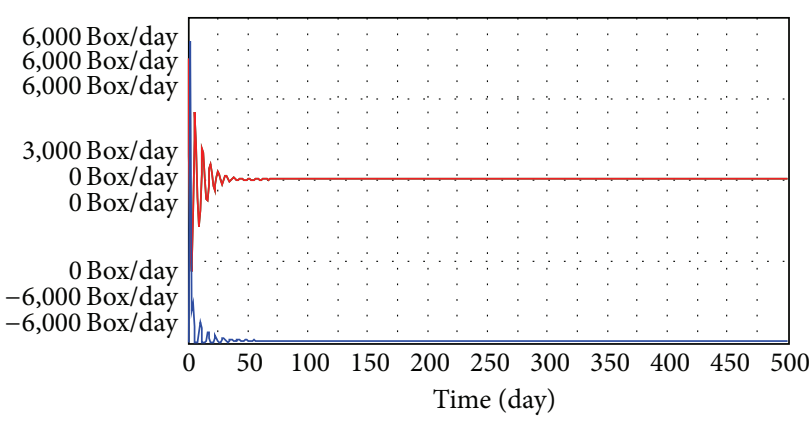

Manufacturer's production order: current - Box/day
"Retailer's production order 1": current $\quad$ Box/day
"Retailer's production order 2": current $\quad$ Box/day

FIGURE 9: Changes of the order quantity of each member when recycled product delay time is 14 .

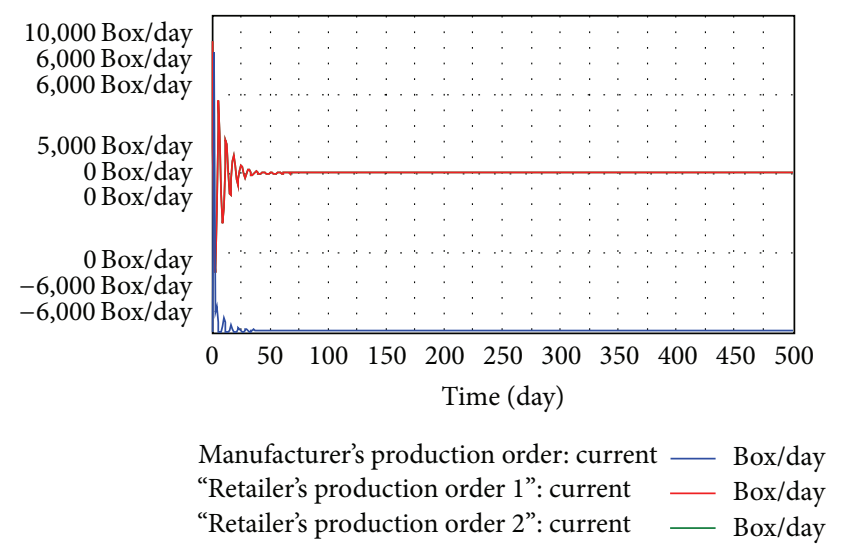

FIgURE 10: Changes of the order quantity of each member when recycled product delay time is 21 .

reduce and the bullwhip effect will diminish. (3) When the proportion of recycled parts recyclers is lowered, manufacturers, Retailer 1, and Retailer 2 inventory fluctuation will increase and the bullwhip effect will be enhanced. (4) When recyclers recycling product delays increased, volatility manufacturers order quantity will rise, but there is little change in the amount of fluctuation of orders of two retailers. (5) When recycling parts recyclers delay increases, fluctuations in the 
TABLE 4: The bullwhip effect when parts recycling delay times are different.

\begin{tabular}{lccc}
\hline & Recyclers reflection coefficient is 1 & Recyclers reflection coefficient is 2 & Recyclers reflection coefficient is 3 \\
\hline Supplier order quantity & 102.412 & 118.521 & 147.502 \\
Retailer 1 order quantity & 88.21 & 89.21 & 92.01 \\
Retailer 2 order quantity & 86.204 & 88.024 & 89.2817 \\
\hline
\end{tabular}

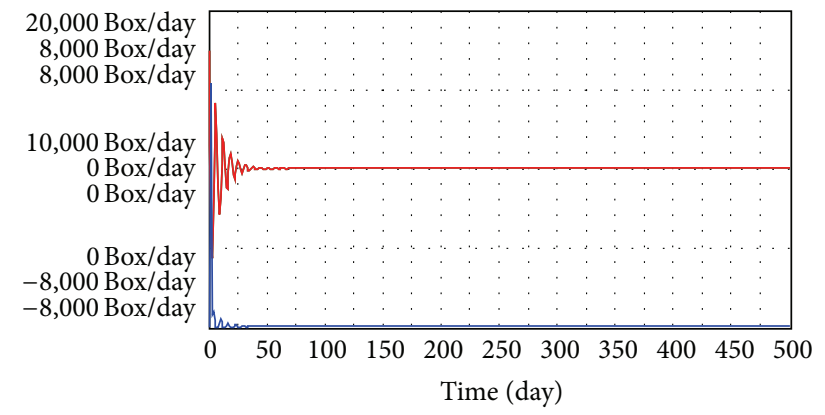

Manufacturer's production order: current — Box/day "Retailer's production order 1": current — Box/day "Retailer's production order 2": current _ Box/day

FIGURE 11: Changes of the order quantity of each member when recycled product delay time is 42 .

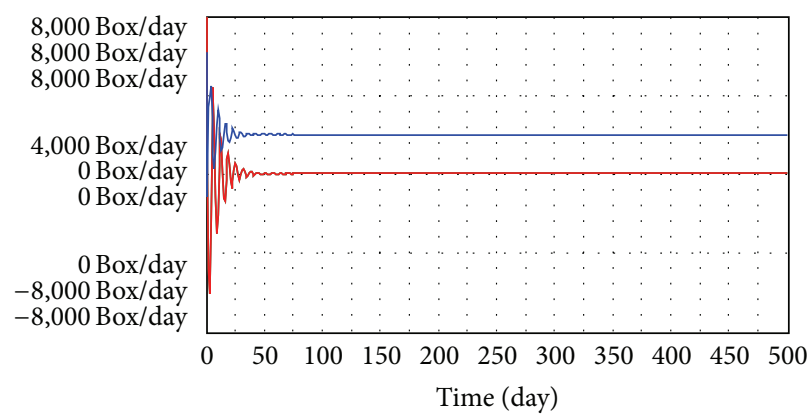

Manufacturer's production order: current — Box/day "Retailer's production order 1": current — Box/day "Retailer's production order 2": current — Box/day

FIGURE 12: Changes of the order quantity of each member when parts recycling delay time is 14 .

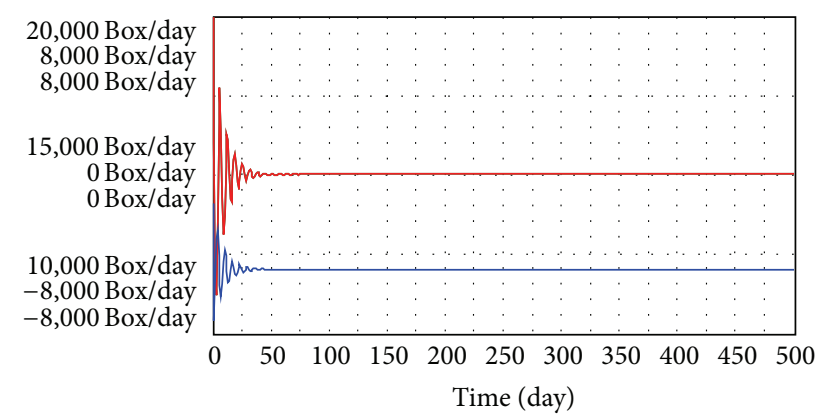

Manufacturer's production order: current — Box/day "Retailer's production order 1": current — Box/day "Retailer's production order 2": current Box/day

FIGURE 13: Changes of the order quantity of each member when parts recycling delay time is 21 .

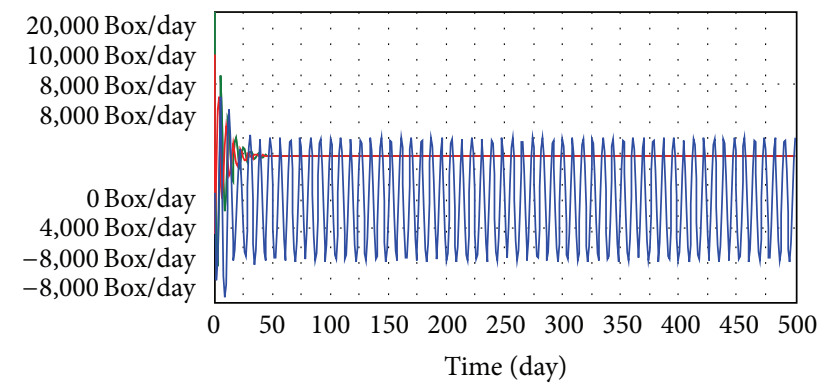

Supplier's production order: current $\quad$ Box/day
Manufacturer's production order: current - Box/day
"Retailer's production order 1": current - Box/day
"Retailer's production order 2": current $\quad$ Box/day

FIGURE 14: Changes of the order quantity of each member when parts recycling delay time is 42 .

supplier order quantity will rise, but there is little change in the amount of fluctuation of orders of two retailers.

\section{Disclosure}

The research interests are supply chain management, distribution network, and regional logistics. Some papers of $\mathrm{Xi}$ gang Yuan is published in Logistics Technology Journal and Journal of Information Technology.

\section{Conflict of Interests}

The authors declare that there is no conflict of interests regarding the publication of this paper.

\section{References}

[1] L. N. van Wassnhove, H. R. Krikke, and J. Q. BloemhofRuwaard, "Design of closed-loop supply chains: a production and return network for refrigerators," Erasmus Research Institute of Management, vol. 17, no. 8, pp. 312-319, 2001.

[2] V. D. R. Guide Jr., V. Jayaraman, and J. D. Linton, "Building contingency planning for closed-loop supply chains with product recovery," Journal of Operations Management, vol. 21, no. 3, pp. 259-279, 2003.

[3] R. C. Savaskan, S. Bhattacharya, and L. N. van Wassenhove, "Closed-loop supply chain models with product remanufacturing," Management Science, vol. 50, no. 2, pp. 239-252, 2004.

[4] R. C. Savaskan and L. N. van Wassenhove, "Reverse channel design: the case of competing retailers," Management Science, vol. 52, no. 1, pp. 1-14, 2006.

[5] J. Forrester, Industrial dynamics, The M.I.T.Press, Cambridge, UK, 1961. 
[6] J. Sterman, Business Dynamics: System Thinking and Modeling for a Complex World, McGraw-Hill/Irwin, 2000.

[7] Y. Baik, Control in the Extended Enterprise, University of Waterloo, 1997.

[8] X. L. Liu, J. H. Ji, and J. L. Li, "The network structure in the supply chain based on the system dynamics simulation," System Engineer, vol. 24, no. 6, pp. 40-45, 2006.

[9] Z. Wan and B. Li, "The bullwhip effect in the closed-loop supply chain based on system dynamics," Computer Integrated Manufacturing Systems, vol. 18, no. 5, pp. 1093-1098, 2012.

[10] J. W. Forrester, "Industrial dynamics: a breakthrough for decision makers," Harvard Business Review, vol. 8, no. 9, pp. 37-66, 1958.

[11] J. L. Burbidge, "The new approach to production," Production Engineer, vol. 40, no. 12, pp. 769-784, 1961.

[12] J. Burbidge, "Five golden rules to avoid bankruptcy," Production Engineer, vol. 62, no. 10, pp. 13-14, 1983.

[13] D. R. Towill, "Forridge-Principles of good practice in material flow," Production Planning and Control, vol. 8, no. 7, pp. 622-632, 1997.

[14] H. L. Lee, V. Padmanabhan, and S. Whang, "Information distortion in a supply chain: the bullwhip effect," Management Science, vol. 43, no. 4, pp. 546-558, 1997.

[15] J. Holmström, "Product range management: a case study of supply chain operations in the European grocery industry," Supply Chain Management, vol. 2, no. 3, pp. 107-115, 1997.

[16] D. R. Towill and P. McCullen, "The impact of an agile manufacturing on supply chain dynamics," International Journal of Logistics, vol. 11, no. 10, pp. 83-96, 1999.

[17] C. F. Daganzo, A Theory of Supply Chains, Institute of Transportation Studies and Department of Civil and Environment Engineering University of California, Berkeley, Calif, USA, 2002.

[18] J. D. Sterman, "Modeling managerial behavior: misperceptions of feedback in a dynamic decision making experiment," Management Science, vol. 35, no. 3, pp. 321-339, 1989. 


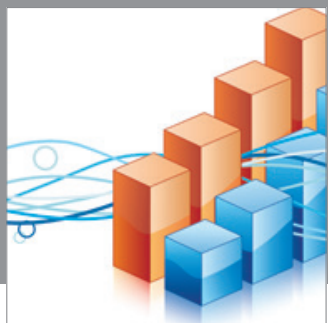

Advances in

Operations Research

mansans

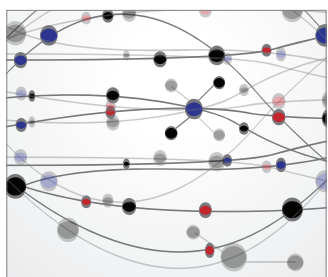

The Scientific World Journal
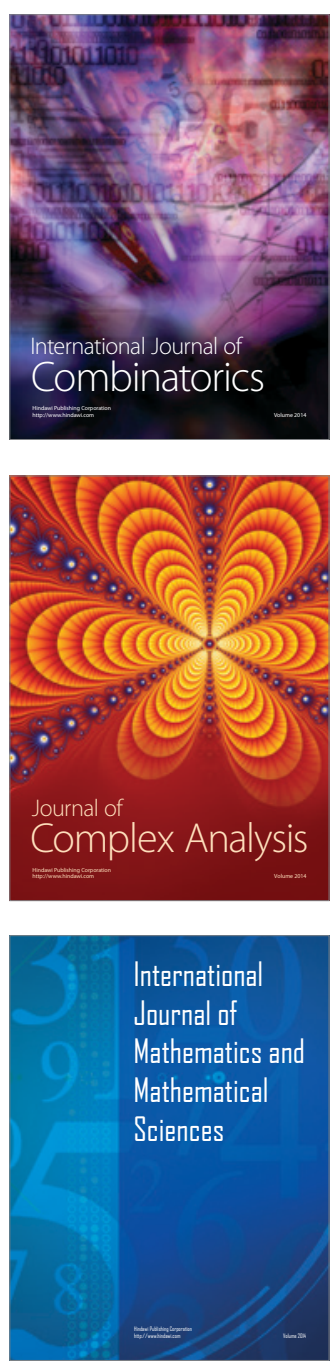
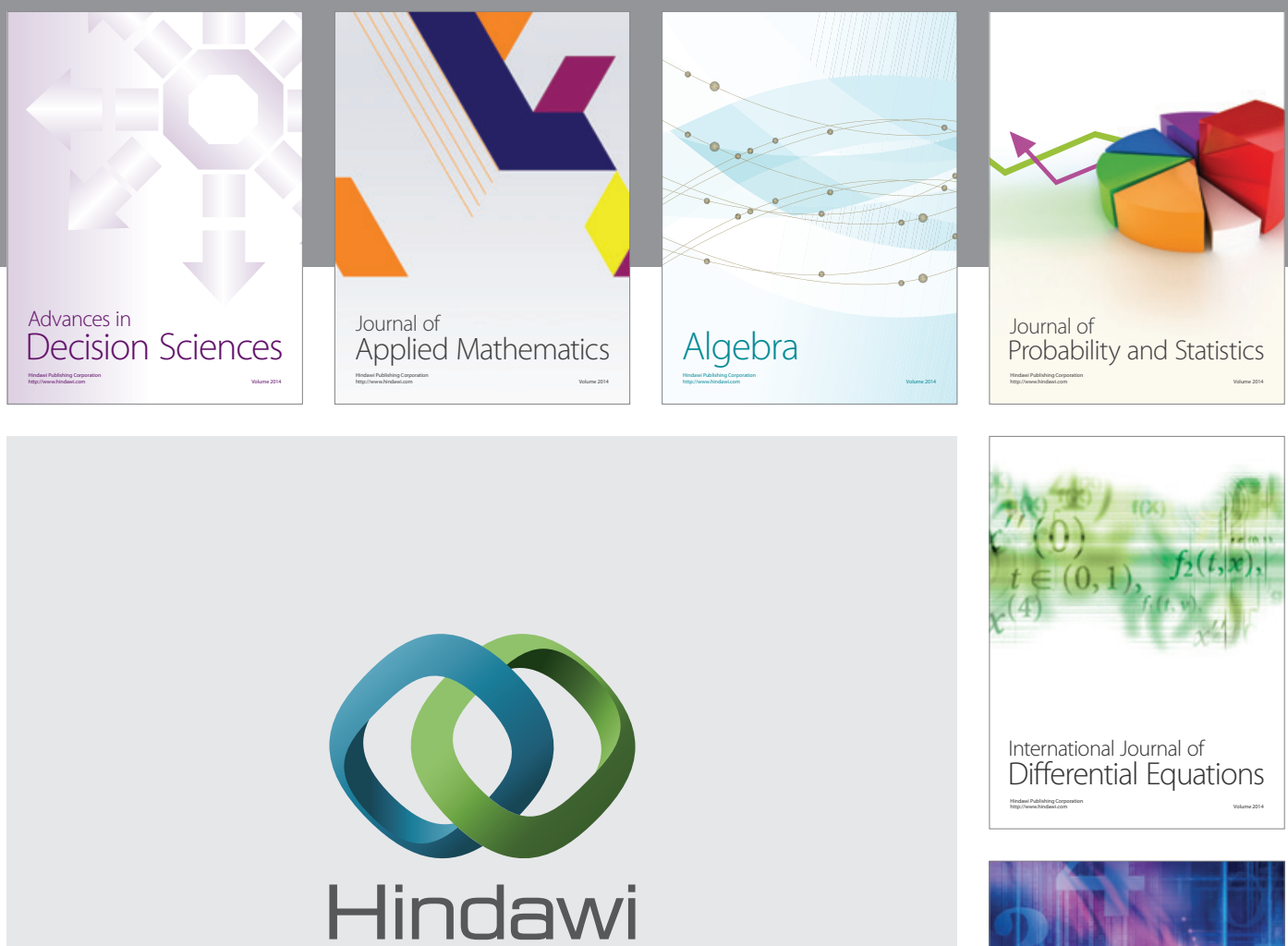

Submit your manuscripts at http://www.hindawi.com
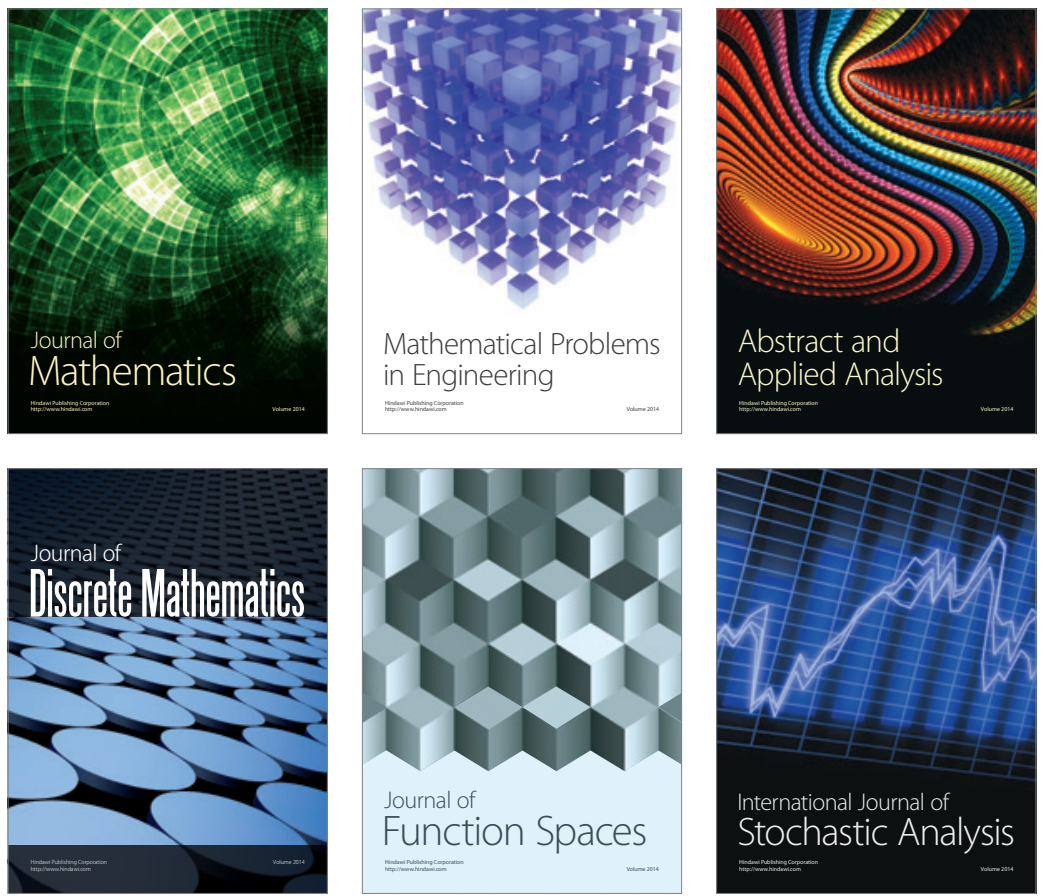

Journal of

Function Spaces

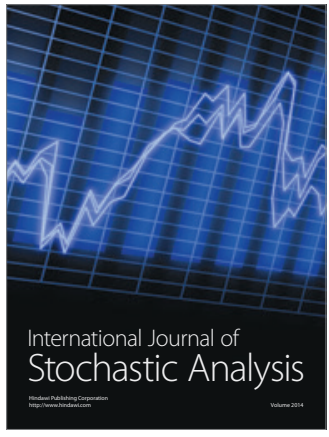

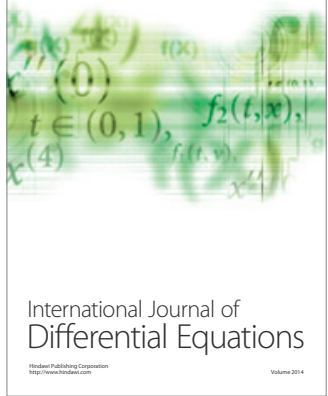
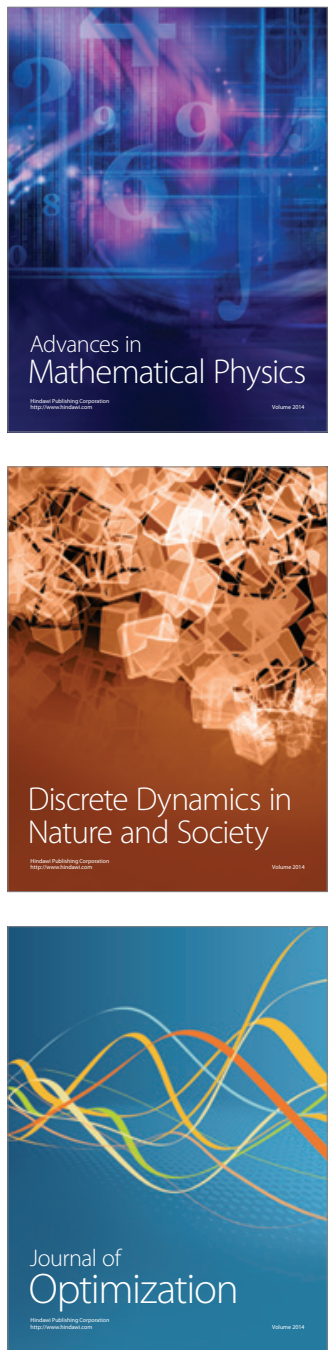